\title{
Participation of children on the autism spectrum in home, school and community
}

Kate Simpson $^{1,2}$, Deb Keen ${ }^{1,2}$, Dawn Adams ${ }^{1,2}$, Clair Alston-Knox ${ }^{3}$, \& Jacqueline Roberts ${ }^{1,2}$ ${ }^{1}$ Autism Centre of Excellence, Griffith University, Australia

${ }^{2}$ Cooperative Research Centre for Living with Autism (Autism CRC), Australia

${ }^{3}$ Griffith Social and Behavioural Research College, Griffith University, Australia

Corresponding author:

Kate Simpson, Autism Centre of Excellence, School of Education and Professional Studies, Griffith University, Messines Ridge Road, Mt Gravatt, Brisbane, QLD 4122, Australia Email: k.simpson@griffith.edu.au

Acknowledgements

The authors acknowledge the work of the LASA team members: Susan Bruck, Trevor Clark, Sandra Devaraj, Robyn Garland, Honey Heussler, Antoinette Hodge, Patricia Howlin, Jessica Paynter, Natalie Silove, David Trembath, Madonna Tucker, Marleen Westerveld, Katrina Williams. The financial support of the Cooperative Research Centre for Living with Autism (Autism CRC), established and supported under the Australian Government's Cooperative Research Centres Program. 


\begin{abstract}

\section{Background}

Children on the autism spectrum participate less frequently, and in a narrower range of activities, than their non-autistic peers but little is known about exact participation patterns across contexts or how this is perceived by caregivers. This study aimed to document patterns of participation and caregiver views with regards to frequency and intensity of activities.
\end{abstract}

\title{
Method
}

Caregivers of children on the spectrum aged $5(n=90)$ and 9-10 years $(n=128)$ completed the Participation and Environment Measure - Child and Youth (PEM-CY) for home, school and community. Caregivers reported on frequency of child's participation, level of involvement and caregivers desire for change in participation patterns.

\section{Results}

Item-level analyses revealed similar patterns of participation across home, school and community for both cohorts with some small age-appropriate differences. Caregivers generally desired increased diversity, frequency and involvement in activities but a decreased use of electronics (computers, games, TV and DVDs).

\section{Conclusion}

The possibility of autism-specific participation patterns could inform future interventions aimed at enhancing social inclusion. This warrants further investigation through multiinformant designs that seek the perspectives of the child and caregivers.

Keywords: autism, children, participation, home, school, community, parents/caregivers 


\section{Participation of children on the autism spectrum in home, school and community}

Characteristics associated with autism, such as atypical ways of thinking, moving, interacting and sensory processing (Walker 2015), may dispose children to participation restrictions. This is defined by the International Classification of Functioning, Disability, and Health: Children and Youth (ICF-CY) as "problems an individual may experience in involvement in life situations” (World Health Organization 2007, p. 12). As such, there has been interest in better understanding participation of children on the autism spectrum across home, school and community contexts. To contribute to our understanding of the participation of children on the autism spectrum across these contexts, this study sought to document patterns of frequency and involvement in activities for two different age cohorts of Australian children on the autism spectrum, using the Participation and Environment Measure - Child and Youth (PEM-CY; Coster et al. 2011).

To date, research on participation of children with disabilities has mainly focused on disability as a whole rather than on diagnostic groups such as autism. Much of this research has also been comparative in nature, contrasting patterns of participation in children with and without disabilities (Khetani et al. 2013, Law et al. 2013, Ullenhag et al. 2014). The need to focus specifically on autism is important as participation patterns may vary considerably across disability types. In particular, autism severity (Hilton et al. 2008, Little et al. 2015), social competence (Reynolds et al. 2011), sensory responsivity (Hochhauser and EngelYeger 2010, LaVesser and Berg 2011, Little et al. 2015, Reynolds et al. 2011), communication (LaVesser and Berg 2011) and behaviour (LaVesser and Berg 2011) have been identified as factors that may impact on participation levels of children on the autism spectrum. 
Studies that have looked specifically at participation of children on the autism spectrum have frequently used the Children's Assessment of Participation and Enjoyment (CAPE; King et al. 2004). This research has provided some information about participation outside school but overlooks the school context that is covered by the PEM-CY used in the current study. When contrasted against an age-matched typically developing group on the CAPE, children on the autism spectrum (6-13 years) with an IQ above 70 consistently show a lower overall frequency of participation in recreational activities than their peers (Hilton et al. 2008, Hochhauser and Engel-Yeger 2010, Potvin et al. 2013). Similar findings have also been reported for preschool age children (LaVesser and Berg 2011) and adolescents (Solish et al. 2010). Children on the autism spectrum have been shown to participate less frequently in formal (structured), informal, recreational activities e.g. playing with toys, watching TV and social activities (Hilton et al. 2008, Hochhauser and Engel-Yeger 2010). Less frequent participation in recreational and social activities, as measured by a purpose-designed instrument called the Activities Questionnaire, was also reported in adolescents on the autism spectrum (Solish et al. 2010). The selection of activities may also be influenced by age. Little et al. (2014) compared three groups of children on the autism spectrum (5-6 years, 7-9 years, 10-12 years) using the Home and Communities Activities Scale (HCAS; adapted from Dunst et al. 2000) and found older children engaged more frequently in outdoor activities and faithbased activities while younger children engaged more frequently in parent-child home activities.

The importance of considering item-level profiles in children on the autism spectrum is highlighted by Potvin et al. (2013) who reported no difference in frequency of participation in social activities, and more frequent participation in recreational activities, when looking at domain scores. However, when explored at item-level, they found children on the autism spectrum generally participated in activities alone or with fewer people and more often with 
family members. Similar findings have been found in a number of studies (Hilton et al. 2008, Hochhauser and Engel-Yeger 2010, Reynolds et al. 2011, Shattuck et al. 2011, Solish et al. 2010). Only once participation levels for home, community, and school are described at the item-level can the specific activities, if any, that are contributing towards these differing participation profiles be identified and further understood.

It is easy to assume that more participation is better (Liptak et al. 2011), however, this may not be the case and little is known about caregiver views on their child's participation levels and whether this changes with age. A child may participate more or less frequently in certain activities than peers but this may give little indication of whether it has a positive or negative impact on the child and whether this is perceived positively or negatively by those around the child. This study investigates the frequency and involvement in activities of children on the autism spectrum aged 5 years and 9-10 years across home, school, and community contexts whilst also documenting caregivers’ perceptions by asking about any desire for change in such behaviours. To do this, we made use of the Longitudinal Study of Australian Students with Autism (LASA) data. LASA is a six-year longitudinal study investigating the developmental trajectories of two cohorts of Australian children on the autism spectrum who were aged 4-5 years and 9-10 years at the commencement of the study in 2015. Children were recruited from across Australia through community service providers, education and health services and are assessed annually using a range of developmental and educational assessments.

\section{Methods}

\section{Data source and sample}

Ethical approval for this study was obtained from participating universities and health authorities. The LASA data set contained a total of 272 children on the autism spectrum across the two age cohorts and the study sample was drawn from this data set. All LASA 
participants who had (a) completed the Social Communication Questionnaire (SCQ; Rutter et al. 2003) and received a cut-off score of $\geq 11$ for autism screening (Lee et al. 2007) and (b) completed the PEM-CY, were included in this study $(n=218)$. Demographic information for this sample (both children and their caregivers) is provided in Table 1.

\section{Table 1}

Child and Caregiver Characteristics by Age Cohorts.

\begin{tabular}{lll}
\hline Demographic variables & 5 yr olds $(\mathrm{n}=90)$ & $9-10$ yr olds $(\mathrm{n}=128)$ \\
$\mathrm{N}(\%)$ & $\mathrm{N}(\%)$
\end{tabular}

Child gender

Male

$75(83.3)$

$102(79.7)$

Female

15 (16.7)

$26(20.3)$

Other medical con/disability

$41(45.6)$

72 (56.3)

Language spoken at home

English

90 (100)

$128(100)$

Caregiver's relationship to the child

Mother

$82(91.1)$

$112(87.5)$

Father

$8(8.9)$

$13(10.2)$

Other

0

$3(2.3)$

Caregiver's age (or mean)

$<30$ years

$9(10)$

31-40 years

$58(64.4)$

$55(43)$

41-50 years

$23(25.6)$

66 (51.6)

$>51$ years

0

$6(4.7)$

Caregiver's highest level of education

No formal/Primary school

0 
Secondary school

Tertiary education

Missing

Caregiver's occupation

Unemployed

Full time employment

Part time employment

Caring responsibilities

Full time study

Part time study

Missing

Annual family income

$<\$ 18200$

$\$ 18,201-\$ 37,000$

$\$ 37,001-\$ 80,000$

$\$ 80,001-\$ 180,000$

$>\$ 180,000$

Do not wish to respond

Missing
$20(22.1)$

28 (21.9)

$70(77.8)$

96 (75)

0

12 (13.3)

$32(25.0)$

34(37.8)

$55(43.0)$

32(35.6)

$29(22.7)$

$2(2.2)$

$3(2.3)$

10(11.1)

0

$1(0.8)$

$\begin{array}{lc}5(5.6) & 5(3.9) \\ 7(7.8) & 11(8.6) \\ 18(20.0) & 26(20.3) \\ 39(43.3) & 59(46.1) \\ 16(17.8) & 13(10.2) \\ 5(5.6) & 12(9.4) \\ 0 & 2(1.6)\end{array}$

2 (1.6)

Both groups displayed a similar demographic profile. The child ratio of males to females was 5:1 and 4:1 in the younger and older groups respectively, consistent with reported rates (Fombonne et al. 2011). In addition, more than $45 \%$ of children had another medical condition or disability. The questionnaires were completed by parents, 
predominantly mothers, with the exception of three other caregivers in the older group. The majority of caregivers had a tertiary education with a family income above $\$ 80,000$.

\section{Participation measure}

Caregivers completed the Participation and Environment Measure for Children and Youth (PEM-CY; Coster et al. 2011). The PEM-CY is a caregiver-report measure of participation and environment of children and youth and includes 25 questions about a child's participation in activities across home (10 items), school (5 items), and community (10 items). Caregivers are asked to rate the frequency of participation on an 8-point scale (from never $=0$ to daily $=$ 7), and level of involvement on a 5-point scale (minimally involved $=1$ to very involved $=5$ ). If caregivers rated a 0 (never) for frequency, they did not provide a rating on the involvement scale. The caregivers' desire for change (yes/no) in their child's participation is also rated together with participation frequency (more or less frequent), involvement (more or less involved) and diversity of activities (greater range of activities). The additional questions on environment were not considered for this particular study. Internal consistency coefficients for measures across contexts ranged from 0.59 to 0.83 . Test-retest reliability was moderate for the school setting (0.58), and good for home and community (0.84 and 0.79 respectively) (Coster et al. 2011).

\section{Data analysis}

SPSS 23 was used for data analysis. Mean and standard deviation scores were calculated on each item of the PEM-CY to provide a description of children's frequency and involvement in activities across home, school, and community. These are reported, even when skew or kurtosis did not reflect a normal distribution, in order to allow for comparison to previous published samples. To further explore the data, median and quartile graphs were used to illustrate the distribution of scores across each item. The percentage of caregivers who reported a desire for change in their child's participation was also calculated for each item. 


\section{Results}

Internal consistency coefficients for 'frequency' were $0.63,0.42,0.57$, and $0.70,0.72$, and 0.73 for 'involvement' across home, school, and community respectively. This indicates that the profiles of scores for children on the autism spectrum differs from the typically developing children and children with developmental disabilities reported by (Coster et al. 2011), and further highlights the importance of discussing the frequency results at item rather than subscale level. Means and standard deviations of the frequency, involvement and caregiver desire for change ratings for each PEM-CY item are presented for Home (Table 2), School (Table 3) and Community (Table 4). Distribution frequencies for each PEM-CY item are presented for Home (Figure 1), School (Figure 2) and Community (Figure 3). The median score for each item is illustrated with a dot. This value represents the score which has $50 \%$ of the data both above and below it. The solid line represents the middle $20 \%$ of the data (quantiles $40 \%$ and $60 \%$ ). On occasion, the median may coincide with one or both of these quantiles. In such a case, the line will be non-symmetrical about the median or obscured completely. These situations represent data that is heavily distributed around a particular score. The dashed lines represent the interquartile range, which is the middle $50 \%$ of the data (quantiles 25\% and 75\%). As with the previous solid segment, it can be obscured by the median or middle $20 \%$ quartile range in cases of high data distribution around a particular score. The fine dotted line represents the 95\% range over which all scores is distributed. 
Table 2

Child Participation and Caregiver Desire for Change: Home Context

\begin{tabular}{|c|c|c|c|c|c|c|c|c|c|c|c|c|c|c|c|c|}
\hline & \multicolumn{8}{|c|}{$\begin{array}{c}\text { Cohort } 1 \text { (5 yrs) } \\
n=90\end{array}$} & \multicolumn{8}{|c|}{$\begin{array}{c}\text { Cohort } 2 \text { (9-10 yrs) } \\
n=128 \\
\end{array}$} \\
\hline & \multirow{2}{*}{$\begin{array}{r}\text { Freq. } \\
(0-7) \\
M(S D)\end{array}$} & \multirow{2}{*}{$\begin{array}{c}\text { Inv. } \\
(1-5) \\
M(S D)\end{array}$} & \multicolumn{6}{|c|}{ Caregiver desire for change (\%) } & \multirow{2}{*}{$\begin{array}{r}\text { Freq. } \\
(0-7) \\
M(S D)\end{array}$} & \multirow{2}{*}{$\begin{array}{r}\text { Invo. } \\
(1-5) \\
M(S D)\end{array}$} & \multicolumn{6}{|c|}{ Caregiver desire for change (\%) } \\
\hline & & & NC & + Freq & -Freq & $+\operatorname{Inv}$ & -Inv & Div & & & NC & + Freq & -Freq & $+\operatorname{Inv}$ & - Inv & Div \\
\hline $\begin{array}{l}\text { 1. Computer and } \\
\text { video games }\end{array}$ & $5.83(2.01)$ & $4.20(1.17)$ & 20.0 & 2 & 41.1 & 12.2 & 18.9 & 25.6 & $6.42(1.49)$ & $4.85(0.50)$ & 7 & 1.6 & 67.2 & 3.1 & 32.0 & 34.4 \\
\hline $\begin{array}{l}\text { 2. Indoor play and } \\
\text { games }\end{array}$ & $6.29(1.40)$ & 3.99(.97) & 24.4 & 36.7 & 0.0 & 42.2 & 1.1 & 26.7 & $5.15(2.00)$ & $3.77(1.21)$ & 14.8 & 48.4 & 2.3 & 34.4 & 1.6 & 39.1 \\
\hline $\begin{array}{l}\text { 3. Arts, crafts, } \\
\text { music and hobbies }\end{array}$ & $5.74(1.53)$ & $3.47(1.22)$ & 20.0 & 46.7 & 0.0 & 46.7 & 1.1 & 25.6 & $5.61(1.60)$ & $3.83(1.13)$ & 17.2 & 49.2 & 0.0 & 35.2 & 1.6 & 40.6 \\
\hline $\begin{array}{l}\text { 4. Watching TV, } \\
\text { videos, and DVDs }\end{array}$ & $6.57(1.19)$ & $4.00(1.10)$ & 27.8 & 2.2 & 45.6 & 10.0 & 16.7 & 8.9 & $6.62(0.77)$ & $4.37(0.90)$ & 21.9 & 0.0 & 53.1 & 2.3 & 23.4 & 18.8 \\
\hline $\begin{array}{l}\text { 5. Getting together } \\
\text { with other people }\end{array}$ & $6.28(1.23)$ & $3.20(1.03)$ & 18.9 & 42.2 & 0.0 & 63.3 & 0.0 & 17.8 & $6.00(1.44)$ & $3.07(1.17)$ & 17.2 & 50.0 & 0.0 & 60.9 & 0.8 & 22.7 \\
\hline $\begin{array}{l}\text { 6. Socialising using } \\
\text { technology }\end{array}$ & $2.76(2.41)$ & $2.45(1.13)$ & 47.8 & 24.4 & 1.1 & 33.3 & 1.1 & 6.7 & $3.85(2.54)$ & $3.37(1.39)$ & 41.4 & 17.2 & 10.9 & 25.0 & 7.8 & 16.4 \\
\hline $\begin{array}{l}\text { 7. Household } \\
\text { chores }\end{array}$ & $4.16(2.65)$ & $2.44(1.08)$ & 11.1 & 50.0 & 0.0 & 65.6 & 1.1 & 16.7 & $5.45(1.99)$ & $2.47(1.29)$ & 14.8 & 59.4 & 0.0 & 63.3 & 0.8 & 22.7 \\
\hline $\begin{array}{l}\text { 8. Personal care } \\
\text { management }\end{array}$ & $6.30(1.86)$ & $2.86(1.19)$ & 13.3 & 41.1 & 0.0 & 66.7 & 0.0 & 12.2 & $6.88(0.73)$ & $3.02(1.27)$ & 17.2 & 35.9 & 0.8 & 65.6 & 1.6 & 17.2 \\
\hline $\begin{array}{l}\text { 9. School } \\
\text { preparation }\end{array}$ & $4.04(3.12)$ & $2.32(1.27)$ & 16.7 & 41.1 & 0.0 & 64.4 & 0.0 & 13.3 & $5.52(2.41)$ & $2.39(1.45)$ & 15.6 & 46.9 & 0.0 & 65.6 & 0.8 & 18.0 \\
\hline 10. Homework & $4.83(2.67)$ & 2.95(1.17) & 30.0 & 28.9 & 1.1 & 50.0 & 0.0 & 8.9 & $5.35(2.23)$ & $2.52(1.22)$ & 15.6 & 44.5 & 0.0 & 67.2 & 1.6 & 15.6 \\
\hline
\end{tabular}




\section{Home}

The means and standard deviations for the Home items are presented in Table 2. The median and quartiles are presented in Figure 1. Children aged 5 years most frequently participated in indoor play/games, watching TV/videos/DVDs, getting together with other people, and personal care management (mean frequency ratings $\geq 6$, "a few times a week" or above, median 7). Socialising using technology was the least frequently attended activity (mean frequency rating 2.76, median 2). Computer and video games presented with a skewed distribution (mean frequency 5.83, median 7 and high distribution between 6 and 7). Children were most involved in computer and video games (mean frequency 4.20, median 5). As shown in Figure 1, both indoor play and games, and watching TV, videos and DVDs have a heavy distribution of scores 4 and above. With the exception of socialising using technology, the majority of caregivers wanted the frequency and/or involvement of the remaining nine items to change. For most items, caregivers wanted increased frequency and involvement, however, over $40 \%$ desired a decrease in frequency of computer and video games (41.1\%) and watching TV/videos/DVDs (45.6\%), with a corresponding desire for decrease in involvement in those activities (18.9\% and 16.7\% respectively). Caregivers most frequently reported a desire for an increase in diversity of activities. 

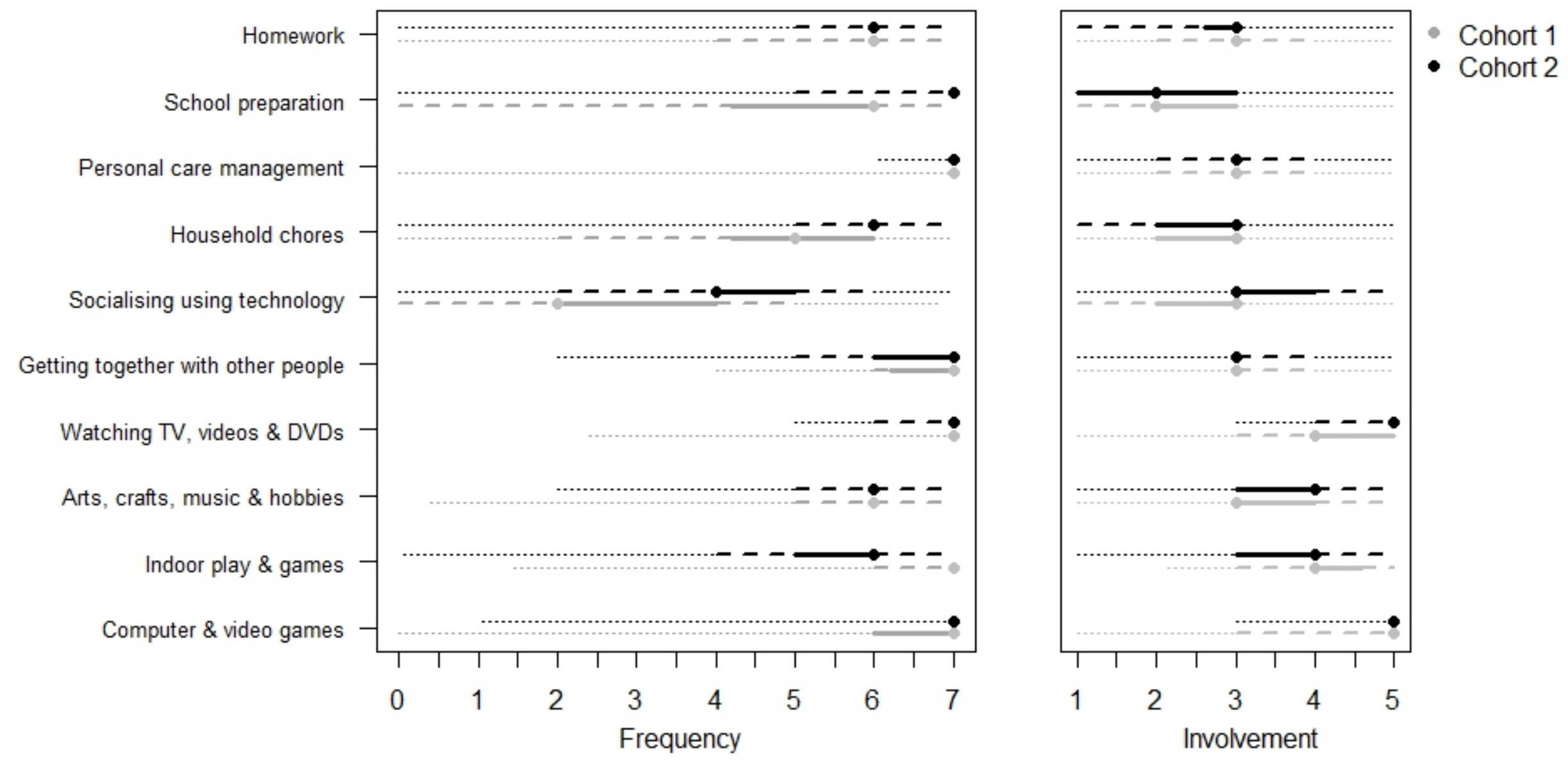

Figure 1 Participation in home items 
A similar pattern was noted for the 9-10 year olds; the most frequently attended activities (mean ratings $\geq 6$, median 7) were computer and video games, watching TV/videos/DVDs, getting together with other people, and personal care management. Children were most involved in computer and video games (4.85) and watching TV/videos/DVDs (4.37), and least involved in household chores (2.47), school preparation (2.39), and homework (2.52), with similar median scores reported. Socialising using technology (mean frequency rating 3.85, median 4) was again the least frequently reported activity, with a similar proportion (41.4\%) of caregivers not desiring change in participation levels of this activity. Desire for increased frequency and involvement was generally reported for all other items with the exception of computer and video games (decreased frequency 67.2\%, decreased involvement 32\%) and watching TV/videos/DVDs (decreased frequency 53.1\%, decreased involvement 23.4\%). Caregivers in the younger and older groups desired an increase in diversity of activities in computer and video games (25.6\% and 34.4\% respectively), indoor play and games (26.7\% and 39.1\% respectively), and arts, crafts, music and hobbies ( $25.6 \%$ and $40.6 \%$ respectively), with the desire more pronounced in the older group. 
Table 3

Child Participation and Caregiver Desire for Change: School Context

\begin{tabular}{|c|c|c|c|c|c|c|c|c|c|c|c|c|c|c|c|c|}
\hline & \multicolumn{8}{|c|}{$\begin{array}{c}\text { Cohort } 1 \text { (5 yrs) } \\
n=90\end{array}$} & \multicolumn{8}{|c|}{$\begin{array}{c}\text { Cohort } 2 \text { (9-10 yrs) } \\
n=128\end{array}$} \\
\hline & \multirow{2}{*}{$\begin{array}{r}\text { Freq. } \\
(0-7) \\
M(S D)\end{array}$} & \multirow{2}{*}{$\begin{array}{r}\text { Invol. } \\
(1-5) \\
M(S D)\end{array}$} & \multicolumn{6}{|c|}{ Caregiver desire for change (\%) } & \multirow{2}{*}{$\begin{array}{r}\text { Freq. } \\
(0-7) \\
M(S D)\end{array}$} & \multirow{2}{*}{$\begin{array}{r}\text { Invol. } \\
(1-5) \\
M(S D)\end{array}$} & \multicolumn{6}{|c|}{ Caregiver desire for change (\%) } \\
\hline & & & $\mathrm{NC}$ & + Freq & -Freq & + In & -In & Div & & & NC & + Freq & -Freq & + In & -In & Div \\
\hline $\begin{array}{l}\text { 1.Participate in } \\
\text { classroom } \\
\text { activities }\end{array}$ & $6.44(1.54)$ & $3.36(1.07)$ & 18.9 & 34.4 & 0.0 & 58.9 & 0.0 & 22.2 & $6.55(1.40)$ & $3.15(.98)$ & 17.2 & 41.4 & 0.0 & 65.6 & 1.6 & 30.5 \\
\hline $\begin{array}{l}\text { 2. Field trips and } \\
\text { school events }\end{array}$ & $1.57(1.70)$ & $3.11(1.23)$ & 31.1 & 27.8 & 0.0 & 44.4 & 0.0 & 17.8 & $2.09(1.32)$ & $3.62(1.01)$ & 34.4 & 28.9 & 0.0 & 43.8 & 1.6 & 21.9 \\
\hline $\begin{array}{l}\text { 3. School teams, } \\
\text { clubs, and } \\
\text { organisations }\end{array}$ & $.94(1.93)$ & $2.18(1.41)$ & 36.7 & 26.7 & 0.0 & 41.1 & 0.0 & 23.3 & $2.50(2.46)$ & $3.33(1.29)$ & 23.4 & 35.9 & 0.0 & 53.9 & 1.6 & 30.5 \\
\hline $\begin{array}{l}\text { 4. Getting together } \\
\text { with peers outside } \\
\text { of class }\end{array}$ & $5.18(2.62)$ & $2.93(1.19)$ & 14.4 & 43.3 & 0.0 & 67.8 & 2.2 & 16.7 & $5.37(2.46)$ & $3.37(1.28)$ & 20.3 & 43.8 & 0.0 & 52.3 & 1.6 & 23.4 \\
\hline $\begin{array}{l}\text { 5. Special roles at } \\
\text { school }\end{array}$ & $.34(1.05)$ & $1.81(1.28)$ & 57.8 & 16.7 & 0.0 & 27.8 & 0.0 & 11.1 & $.76(1.70)$ & $2.74(1.45)$ & 34.4 & 29.7 & 0.0 & 43.8 & 1.6 & 25.8 \\
\hline
\end{tabular}




\section{School}

The means and standard deviations for the School items are presented in Table 3. The median and quartiles are presented in Figure 2. The items in this subscale were not normally distributed, with measures of skew and kurtosis suggesting a ceiling effect on frequency of participation in classroom activities and getting together with peers outside of class, and a floor effect for the frequency of participation in field trips, and special roles. Only six children in the younger cohort participated in school teams and clubs. Given this, the means and standard deviations reported in the School section below need to be interpreted with caution, with distribution pattern more clearly displayed in Figure 2.

Caregivers reported that children in both age groups (5 years and 9-10 years) attended classroom activities at least several times a week on average (mean 6.44 and 6.55 respectively, median 7) and got together with peers outside of class on average at least once per week (mean 5.18 and 5.37 respectively, median 6 and 7 respectively). Median involvement levels in both groups was 3 or below, although Figure 2 shows higher involvement distribution for the older group. Both cohorts of children rarely participated in special roles at school (mean .34 and .76 respectively, median 0). While only $16.7 \%$ of caregivers in the younger group would like to see their child participate in such special roles more often, almost double (29.7\%) the number of caregivers in the older age group would like such activities to increase.

Some cohort specific patterns can be identified. Caregivers of the younger cohort (5 years) rated getting together with peers outside class as the item most requiring increased frequency (43.3\%) and involvement (67.8\%), and would like their child to be more involved in classroom activities (58.9\%) and a more diverse range of these activities (22.2\%). Caregivers of the older children reported a desire for increased frequency and involvement in classroom activities (41.4\% and 65.6\% respectively) and getting together with peers outside 
of class (43.8\% and 52.3\% respectively). Over $40 \%$ of caregivers desired their child to be more involved in all school activities, with a desire for more diverse activity participation identified particularly in classroom activities (30.5\%) and school teams (30.5\%). 

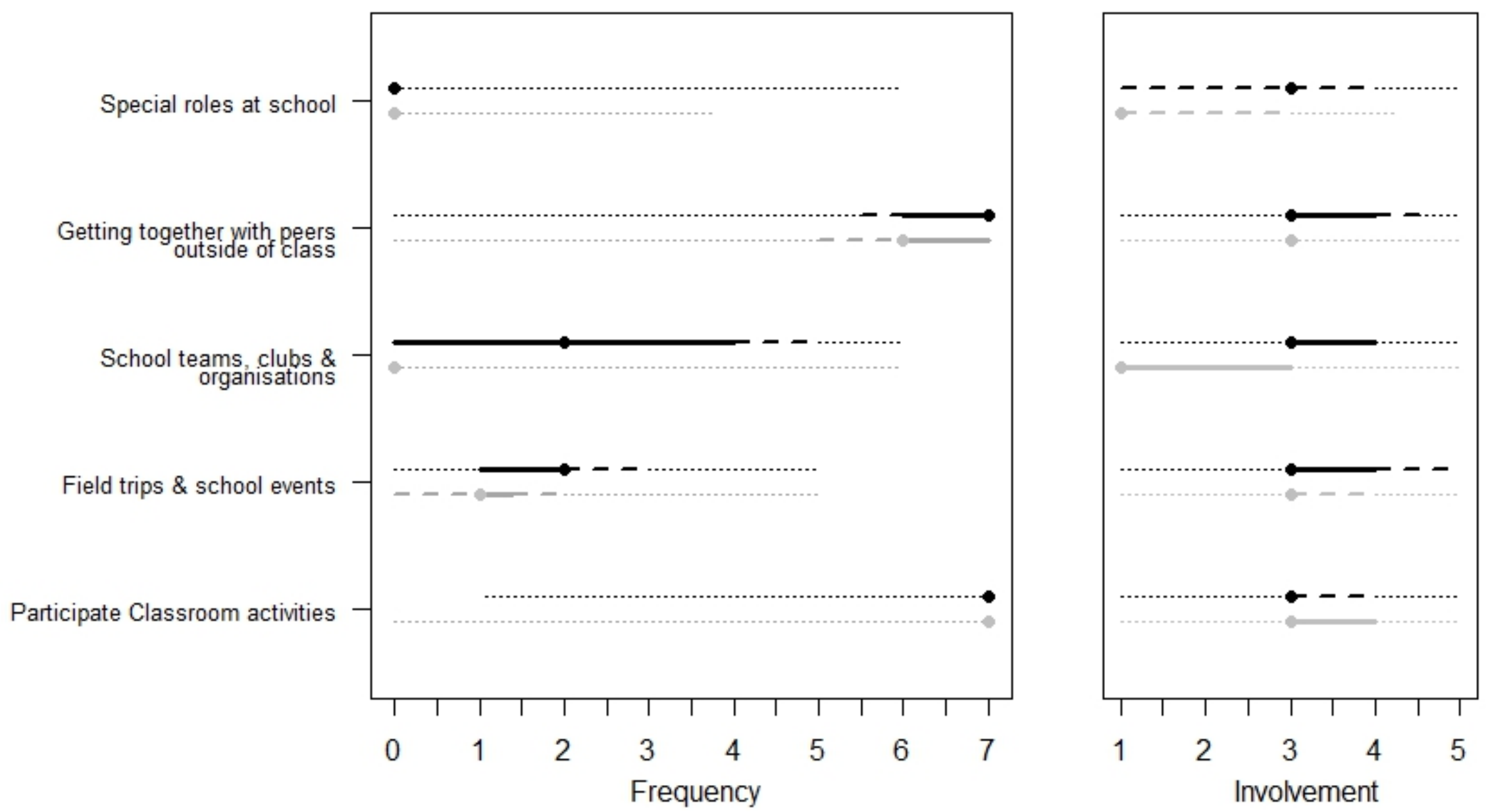

Cohort 1

- Cohort 2

Figure 2 Participation in School items 
Table 4 Child Participation and Caregiver Desire for Change: Community Context

\begin{tabular}{|c|c|c|c|c|c|c|c|c|c|c|c|c|c|c|c|c|}
\hline & \multicolumn{8}{|c|}{$\begin{array}{l}\text { Cohort } 1 \text { (5 yrs) } \\
\quad n=90\end{array}$} & \multicolumn{8}{|c|}{$\begin{array}{c}\text { Cohort } 2 \text { (9-10 yrs) } \\
n=128\end{array}$} \\
\hline & \multirow{2}{*}{$\begin{array}{r}\text { Freq. } \\
(0-7) \\
M(S D)\end{array}$} & \multirow{2}{*}{$\begin{array}{c}\text { Invol. } \\
(1-5) \\
M(S D)\end{array}$} & \multirow[b]{2}{*}{ NC } & \multicolumn{5}{|c|}{ Caregiver desire for change (\%) } & \multirow{2}{*}{$\begin{array}{l}\text { Freq. } \\
(0-7) \\
M(S D)\end{array}$} & \multirow{2}{*}{$\begin{array}{r}\text { Invol. } \\
(1-5) \\
M(S D)\end{array}$} & \multicolumn{6}{|c|}{ Caregiver desire for change (\%) } \\
\hline & & & & + Freq & -Freq & + In & -In & Div & & & NC & +Freq & -Freq & + In & -In & Div \\
\hline $\begin{array}{l}\text { 1. Neighbourhood } \\
\text { outings }\end{array}$ & $5.02(1.32)$ & $3.45(1.12)$ & 26.7 & 36.7 & 0.0 & 42.2 & 0.0 & 26.7 & $4.83(1.48)$ & $3.30(1.22)$ & 28.1 & 30.5 & 0.0 & 43.8 & 0.8 & 32.0 \\
\hline $\begin{array}{l}\text { 2. Community } \\
\text { events }\end{array}$ & $1.98(1.61)$ & $2.96(1.32)$ & 24.4 & 47.8 & 1.1 & 34.4 & 0.0 & 23.3 & $1.91(1.45)$ & $3.00(1.14)$ & 26.6 & 43.0 & 0.0 & 42.2 & 0.8 & 32 \\
\hline $\begin{array}{l}\text { 3. Organised } \\
\text { physical activities }\end{array}$ & $2.27(2.55)$ & $3.15(1.42)$ & 30.0 & 42.2 & 0.0 & 37.8 & 0.0 & 25.6 & $2.98(2.55)$ & $3.52(1.24)$ & 23.4 & 44.5 & 0.0 & 49.2 & 0.8 & 28.1 \\
\hline $\begin{array}{l}\text { 4. Unstructured } \\
\text { physical activities }\end{array}$ & 4.71(1.99) & $3.80(1.10)$ & 27.8 & 45.6 & 1.1 & 35.6 & 0.0 & 26.7 & $4.66(1.88)$ & $3.61(1.08)$ & 19.5 & 57.0 & 0.8 & 47.7 & 0.8 & 31.3 \\
\hline $\begin{array}{l}\text { 5. Classes and } \\
\text { lessons }\end{array}$ & $1.10(2.14)$ & $2.56(1.58)$ & 41.1 & 33.3 & 1.1 & 20.0 & 0.0 & 25.6 & $1.47(2.25)$ & $3.72(1.28)$ & 35.9 & 36.7 & 1.6 & 32.0 & 0.0 & 28.1 \\
\hline $\begin{array}{l}\text { 6. Organisations, } \\
\text { groups, clubs, and } \\
\text { volunteer or } \\
\text { leadership } \\
\text { activities }\end{array}$ & $0.22(0.99)$ & $1.56(1.23)$ & 62.2 & 21.1 & 0.0 & 17.8 & 0.0 & 13.3 & $0.88(1.84)$ & $3.17(1.42)$ & 42.2 & 29.7 & 0.0 & 25.0 & 1.6 & 22.7 \\
\hline $\begin{array}{l}\text { 7. Religious or } \\
\text { spiritual gatherings }\end{array}$ & $1.32(2.13)$ & $2.23(1.26)$ & 71.1 & 12.2 & 0.0 & 17.8 & 2.2 & 5.6 & $1.36(2.04)$ & $2.47(1.28)$ & 57.0 & 10.2 & 4.7 & 20.3 & 5.5 & 9.4 \\
\hline $\begin{array}{l}\text { 8. Getting together } \\
\text { with other children } \\
\text { in the community }\end{array}$ & $2.76(1.90)$ & $3.00(1.05)$ & 21.1 & 60 & 1.1 & 52.2 & 0.0 & 23.3 & $2.62(1.98)$ & $3.46(1.09)$ & 21.9 & 56.3 & 0.8 & 46.1 & 0.0 & 22.7 \\
\hline 9. Working for pay & $0.10(0.74)$ & $1.09(0.42)$ & 80.0 & 7.8 & 1.1 & 6.7 & 1.1 & 4.4 & $1.31(2.25)$ & $2.44(1.13)$ & 60.9 & 19.5 & 3.1 & 18.8 & 1.6 & 11.7 \\
\hline $\begin{array}{l}\text { 10. Overnight } \\
\text { visits or trips }\end{array}$ & $0.85(1.19)$ & $3.14(1.51)$ & 74.4 & 16.7 & 0.0 & 11.1 & 1.1 & 10.0 & $1.22(1.27)$ & 3.68(1.18) & 46.1 & 35.2 & 0.8 & 25.8 & 0.8 & 15.6 \\
\hline
\end{tabular}




\section{Community}

The means and standard deviations for the Community items are presented in Table 4. The median and quartiles are presented in Figure 3. As expected, a number of items in this section relating to structured clubs or lessons had non-normally distributed profiles, with most children being rated as either participating in an activity once per week or not participating at all. Means and standard deviations are reported to allow comparison to previous samples but should be interpreted appropriately.

Children in both age groups participated most frequently in neighbourhood outings (mean 5.02 and 4.83 respectively, median 5) and unstructured physical activities (4.71 and 4.66, median 5). The remaining activities were most frequently rated as occurring once a month or less, with frequency mean ratings ranging from 0.10 (working for pay) to 2.76 (getting together with other children) for children (5years) and 0.88 (organisations/groups/clubs) to 2.98 (organised physical activities) for older children (9-10 years). As shown in Figure 3, within and between group differences were most pronounced on frequency of attending organised physical activities. Older children attended this activity more frequently, however, there was a wide central distribution in both groups. When children attended community activities, their mean and median involvement was 4 or below, with older children displaying higher involvement levels. 

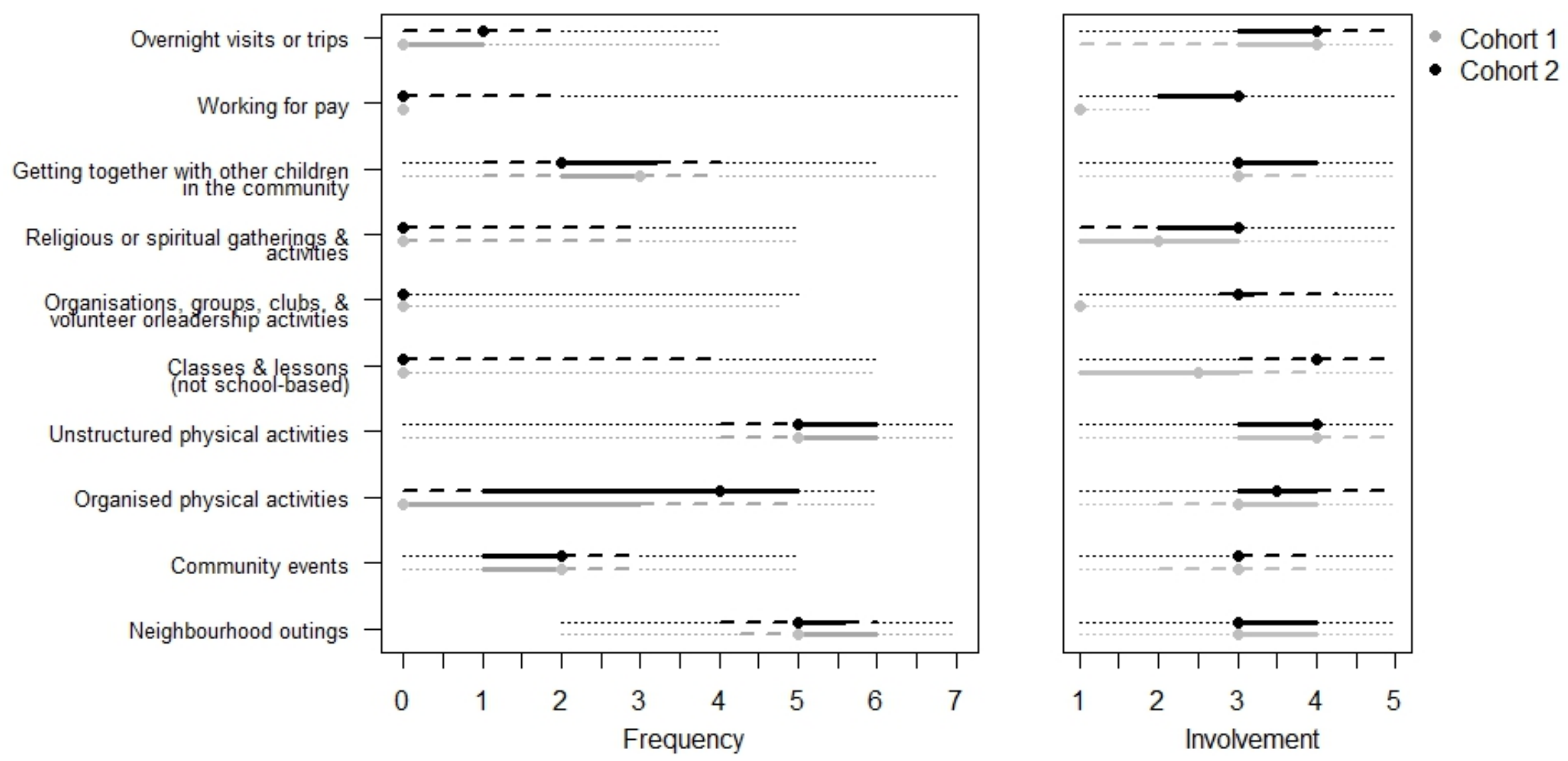

Figure 3 Participation in community items 
The majority of caregivers of the younger children desired no change in organisational groups (62.2\%), religious or spiritual gatherings (71.1\%), working for pay (80\%), and overnight visits or trips (74.4\%). The highest item rated for change in frequency (60\%) and involvement (52.2\%) was getting together with other children in the community. There was variability in caregiver responses on classes and lessons, with $41.1 \%$ of caregivers desiring no change compared with 33.3\% desiring increased frequency.

Similar overall patterns in caregiver responses to community participation were reported in the older group. The majority of caregivers desired no change in their child's current participation in religious or spiritual gatherings (57\%) and working for pay (60\%). The items rated highest for change in both frequency and involvement were unstructured physical activities (57\% and $47.7 \%$ respectively), and getting together with other children in the community (56.3\% and 46.1\% respectively). Responses were more variable for neighbourhood outings, classes and lessons, and overnight visits or trips.

\section{Discussion}

The results from this study provide a valuable contribution to our understanding about patterns of participation across home, school and in the community for children on the autism spectrum aged 5 years and 9-10 years of age. The large sample size and analysis of participation at the item level of the PEM-CY provides a rich source of information about participation levels in these age groups. Children in both age groups, most frequently participated in and were most involved in computer and video games, followed by watching TV, videos and DVDs. Parents most desired a decrease in their child's participation in these activities. High levels of frequency and involvement were also reported in indoor play in the younger group.

The value of the data in this paper is further highlighted when contrasted with previously published data of children with and without disabilities (e.g. Coster et al. 2013). 
Some scores were comparable between the samples: for example, the frequency of participation in classroom activities and field trips, suggesting that there is some commonality between the schooling experiences. However, the mean score for special roles at school for children on the autism spectrum aged 9-10 in this sample was .76 (SD 1.70), compared to a mean of 4.09 for primary school aged children with mixed disabilities of mixed aetiologies, and 4.15 for children without disabilities. Similarly, the caregivers of children aged 9-10 on the autism spectrum in this sample reported a mean average frequency of 2.5 (SD 2.46) for school teams and clubs, compared to 3.64 (SD 1.79) for children with disabilities and 4.31 (SD 1.8) for children without disabilities in Coster et al.'s study. Caution is required when interpreting these results. Cultural differences between the education systems in Australia (where this study was conducted) and Canada and the USA (where the Coster et al. study was conducted) may have contributed to these results. Differences between the different samples were more marked on frequency and it is not possible from the data to determine if this was due to a lack of opportunity. Despite this, even when frequenting these activities, lower levels of involvement were scored. It is concerning that differences are notable between children on the autism spectrum and other children with and without disabilities, and even more concerning that these are present as young as five years old, suggesting that patterns of difference may be established right from the start of school. It may be that children on the autism spectrum do not simply have lower participation than their typically-developing peers (Hilton et al. 2008, Hochhauser and Engel-Yeger 2010, Potvin et al. 2013), but that this is both qualitatively and quantitatively different in specific ways. As participation in school has an impact on positive youth development (Weiss and Burnham Riosa 2015), these differences should be considered and planned for throughout a child's academic career. 
The low participation rate for socializing using technology for both age cohorts may seem unexpected in light of the reported interest in digital technologies shown by those on the spectrum (Ploog et al. 2013). This finding is consistent with research by Mazurek and Wenstrup (2013) who found children on the autism spectrum aged 8-18 years spent little time using social media or socially interactive video games. These researchers also found that compared to typically developing siblings, the autism spectrum disorders group spent more time watching television and playing video games and had higher levels of problematic video game use. This may explain why caregivers in this study, although generally desiring increased frequency and involvement in home activities, actually wanted decreased involvement in screen-based activities like TV and video games. This desire for reduced participation in these activities was even greater for the older age cohort. Conversely, almost half of the caregivers did not desire change to the frequency of participation in socializing using technology. Further research could investigate how a relative strength and interest in solitary screen-based activities might be extended to enhance participation in socially interactive technologies/social media.

Most notable in the school and community contexts for both age cohorts in this study were the caregivers' desire for increased participation in activities involving other children. This desire for change occurred in relation to frequency and diversity of activities and level of involvement in these activities. If children on the autism spectrum are to be included in mainstream settings, participation in the types of activities identified in both the school and community areas of the PEM-CY are important. Approximately $21 \%$ of students on the autism spectrum are excluded from school at least once and teachers report they lack training and support to provide for such students who are often the targets of bullying (Humphrey 2008, Roberts and Simpson 2016). Further research into participation at school for these students from the Foundation year onwards is needed. The data in this study is based on 
caregiver reports and future research could also consider child and teacher reports to triangulate data and get a more rounded picture of the child's experience at school, and how school participation can best be fostered. Given the identification of a range of areas that children on the autism spectrum engage in less frequently than their peers with and without disabilities, it could be tempting to focus upon methods or interventions to increase frequency of participation in these areas. However, little is known about the experience and desires of the children themselves, nor about the underlying reasons for caregivers' desires of more (or less) engagement in specific activities or about the factors (including social or financial) that may be influencing participation patterns. Future work should consider such aspects and ideally employ multi-informant designs to build a larger, more detailed understanding of the child within their social and educational context.

These findings should be considered in the context of the study limitations. The data were all obtained through an online questionnaire from caregivers who were recruited into a six-year longitudinal study and were predominantly from similar socio-economic backgrounds, potentially biasing the sample. Whilst the methodology allowed for the collection of two large cohorts of data, it did not allow for direct observations of the child's participation nor for a direct measure of autism symptoms or cognitive ability. The sample is also Australian, where inclusion of children on the autism spectrum into mainstream schools and community groups may occur more or less frequently than in other locations of the world. 


\section{Key findings}

- Exploration at the item level identifies a mix of participation levels for children on the autism spectrum in home, school and community contexts

- Low internal consistency on some subscales indicate participation profiles for children on the autism spectrum differ from those previously published for both typically developing children and children with developmental disabilities

- Caregivers of both the 5 and 9-10 year old children with autism generally desired an increase in their child's participation frequency and involvement in activities as well as a desiring engagement in a broader diversity of activities

- Results highlight the importance of further studies exploring causes and consequences of participation patterns at school 


\section{References}

Coster, W., Bedell, G., Law, M., Khetani, M. A., Teplicky, R., Lilfenquist, K., Gleason, K. \& Kao, Y.-C. (2011) Psychometric evaluation of the participation and environment measure for children and youth. Developmental Medicine \& Child Neurology, 53, 1030-1037.

Coster, W., Law, M., Bedell, G., Liljenquist, K., Kao, Y. C., Khetani, M. \& Teplicky, R. (2013) School participation, supports and barriers of students with and without disabilities. Child: Care, Health and Development, 39, 535-543.

Dunst, C. J., Hamby, D., Trivette, C. M., Raab, M. \& Bruder, M. B. (2000) Everyday family and community life and children's naturally occurring learning opportunities. Journal of Early Intervention, 23, 151-164.

Egilson, S. T., Jakobsdóttir, G. \& Ólafsdóttir, L. B. (2017) Parent perspectives on home participation of high-functioning children with autism spectrum disorder compared with a matched group of children without autism spectrum disorder. Autism, 1362361316685555.

Fombonne, E., Quirke, S. \& Hagen, A. (2011) Epidemiology of pervasive developmental disorders. In: Autism spectrum disorders (eds. Amaral, D. G., Dawson, G. \& Geschwind, D. H.), pp. 90-111. Oxford University Press, City.

Hilton, C. L., Crouch, M. C. \& Israel, H. (2008) Out-of-school participation patterns in children with high-functioning autism spectrum disorders. American Journal of Occupational Therapy, 62, 554-563.

Hochhauser, M. \& Engel-Yeger, B. (2010) Sensory processing abilities and their relation to participation in leisure activities among children with high-functioning autism spectrum disorder (HFASD). Research in Autism Spectrum Disorders, 4, 746-754.

Humphrey, N. (2008) Including pupils with autistic spectrum disorders in mainstream schools. Support for Learning, 23, 41-47.

Khetani, M., Graham, J. E. \& Alvord, C. (2013) Community participation patterns among preschool-aged children who have received Part C early intervention services. Child: Care, Health and Development, 39, 490-499.

King, G., Law, M., King, S., Hurley, P., Rosenbaum, P., Hanna, S. E., Kertoy, M. \& Young, N. (2004) Children's assessment of participation and enjoyment (CAPE), PsychCorp, San Antonia, TX.

Lavesser, P. \& Berg, C. (2011) Participation patterns in preschool children with an autism spectrum disorder. OTJR: Occupation, Participation and Health, 31, 33-39.

Law, M., Anaby, D., Teplicky, R., Khetani, M. A., Coster, W. \& Bedell, G. (2013) Participation in the home environment among children and youth with and without disabilities. The British Journal of Occupational Therapy, 76, 58-66.

Lee, L.-C., David, A. B., Rusyniak, J., Landa, R. \& Newschaffer, C. (2007) Performance of the Social Communication Questionnaire in children receiving preschool special education services. Research in Autism Spectrum Disorders, 1, 126-138.

Liptak, G. S., Kennedy, J. A. \& Dosa, N. P. (2011) Social participation in a nationally representative sample of older youth and young adults with autism. JOURNAL OF DEVELOPMENTAL AND BEHAVIORAL PEDIATRICS, 32, 277-283.

Little, L. M., Ausderau, K., Sideris, J. \& Baranek, G. (2015) Activity participaton and sensory features among children with autism spectrum disorders. Journal of Autism and Developmental Disorders, 45, 2981-2990. 
Little, L. M., Sideris, J., Ausderau, K. \& Baranek, G. T. (2014) Activity participation among children with autism spectrum disorder. American Journal of Occupational Therapy, 68, 177-185.

Mazurek, M. O. \& Wenstrup, C. (2013) Television, video game and social media use among children with asd and typically developing siblings. Journal of Autism and Developmental Disorders, 43, 1258-1271.

Ploog, B., Scharf, A., Nelson, D. \& Brooks, P. (2013) Use of Computer-Assisted Technologies (CAT) to enhance social, communicative, and language development in children with autism spectrum disorders. Journal of Autism and Developmental Disorders, 43, 301-322.

Potvin, M.-C., Snider, L., Prelock, P., Kehayia, E. \& Wood-Dauphinee, S. (2013) Recreational participation of children with high functioning autism. Journal of Autism and Developmental Disorders, 43, 445-457.

Reynolds, S., Bendixen, R. M., Lawrence, T. \& Lane, S. J. (2011) A pilot study examining activity participation, sensory responsiveness, and competence in children with high functioning autism spectrum disorder. Journal of Autism and Developmental Disorders, 41, 1496-1506.

Roberts, J. \& Simpson, K. (2016) A review of research into stakeholders perspectives on inclusion of students with autism in mainstream schools. International Journal of Inclusive Education, 20, 1084-1096.

Rutter, M., Bailey, A., Berument, S., Lord, C. \& Pickles, A. (2003) Social communication questionnaire, Western Psychological Services, Los Angeles, CA.

Shattuck, P. T., Orsmond, G. I., Wagner, M. \& Cooper, B. P. (2011) Participation in social activities among adolescents with an autism spectrum disorder. PLoS one, 6, e27176.

Solish, A., Perry, A. \& Minnes, P. (2010) Participation of children with and without disabilities in social, recreational and leisure activities. Journal of Applied Research in Intellectual Disabilities, 23, 226-236.

Ullenhag, A., Krumlinde-Sundholm, L., Granlund, M. \& Almqvist, L. (2014) Differences in patterns of participation in leisure activities in Swedish children with and without disabilities. Disability and Rehabilitation, 36, 464-471.

Walker, N. (2015) What is autism? In: The real experts: Readings for parents of autistic children (ed. Sutton, M.), pp. 11-12. Autonomous Press, City.

Weiss, J. A. \& Burnham Riosa, P. (2015) Thriving in youth with autism spectrum disorder and intellectual disability. Journal of Autism and Developmental Disorders, 45, 24742486.

World Health Organization (2007) International Classificaiton of Functioning, Disability and Health: Children and Youth version (ICF-CY), World Health Organization Geneva, Switzerland. 